\title{
Radiation Insult to the Active Bone Marrow as Predicted by a Method of CHORDS
}

\author{
T. D. Jones
}

\section{OAK RIDGE NATIONAL LABORATORY}




\section{DISCLAIMER}

This report was prepared as an account of work sponsored by an agency of the United States Government. Neither the United States Government nor any agency Thereof, nor any of their employees, makes any warranty, express or implied, or assumes any legal liability or responsibility for the accuracy, completeness, or usefulness of any information, apparatus, product, or process disclosed, or represents that its use would not infringe privately owned rights. Reference herein to any specific commercial product, process, or service by trade name, trademark, manufacturer, or otherwise does not necessarily constitute or imply its endorsement, recommendation, or favoring by the United States Government or any agency thereof. The views and opinions of authors expressed herein do not necessarily state or reflect those of the United States Government or any agency thereof. 


\section{DISCLAIMER}

Portions of this document may be illegible in electronic image products. Images are produced from the best available original document. 
Printed in the United States of America: Available from National Technical Information Service

U.S. Department of Commerce

5285 Port Royal Road, Springfield, Virginia 22161

Price: Printed Copy \$4.00; Microfiche \$2.25

This report was prepared as an account of work sponsored by the United States Government. Neither the United States nor the Energy Research and Development Administration, nor any of their employees, nor any of their contractors, subcontractors, or their employees, makes any warranty, express or implied, or assumes any legal liability or responsibility for the accuracy, completeness or usefulness of any information, apparatus, product or process disclosed, or represents that its use would not infringe privately owned rights. 
ORNL/TM-5337

Contract No. W-7405-eng-26

-HEALTH PHYSICS DIVISION

RADIATION INSULT TO THE ACTIVE BONE MARROW

AS PREDICTED BY A METHOD OF CHORDS

T. D. Jones

MARCH 1976

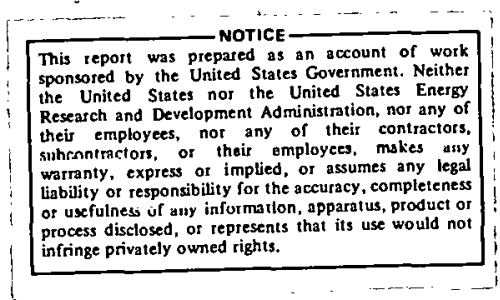

NOTICE This document contains information of a preliminary nature and was prepared primarily for internal use at the Oak Ridge National Laboratory. It is subject to revision or correction and therefore does not represent a final report.

OAK RIDGE NATIONAL LABBORATORY

Oak Ridge, Tennessee 37830

operated by

UNION CARBIDE CORPORATION

for the

ENERGY RESEARCH AND DEVELOPMENT ADMINISTRATION 
THIS PAGE

WAS INTENTIONALLY

LEFT BLANK 
List of Tables....................... iv

List of figures .................. . iv

Abstract. .................. 1

Introduction to the CHORD Concept . . . . . . . . . . 1

CHORD Applications to Red Bone Marrow . . . . . . . . . . 3

CHORD Distribution and Marrow Doses . . . . . . . . . . 7

Other CHORD Applications. . . . . . . . . . . . . . . 21

Conclusions .................... . . 23

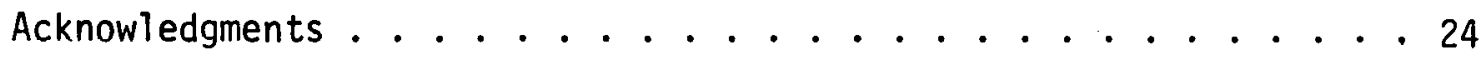

References. . . . . . . . . . . . . 25 


\section{LIST OF FIGURES}

Figure

Page

1. Critical Human Organ Radiation Dosimetry the CHORD

Concept. . . . . . . . .............. 4

2. Distributions of the Active Bone Marrow. . . . . . . . . . 5

3. CHORD Density Functions for Active Marrow in Reference Man . . 8

4. Dose to Active Marrow as Predicted by the CHORD Concept. . . . 11

5. Active Marrow lose Kelatilve lu Exposure at the Front of

the Chest (A-P Exposure)................ . 12

6. Photon Attenuation of Skeletal Tissue Compared to that of

Soft Tissue. . . . . . . . . . . . . . . . . 14

7. Dose to Bone Marrow from a Broad Beam Incident on a

Rotating Phantom . . . . . . . . . . . . . . . 16

8. Dose from Recoil Ions to the Active Marrow as Predicted

by the CHORD Concept ............... . 20

9. Critical Human Organ Radiation Dosimeter . . . . . . . . . 22

\section{LIST OF TARLES}

Table

Page

1. CHORD $p\{\ell\} \triangle \ell$ Values for Active Marrow in Reference Man . . . 9

2. Active Marrow Dose Relative to Dose at the Front of the Chest..................... 15

3. Dose to Active Marrow from Neutron Pruduced Recoil Ions as Predicted by CHORD Distributions. . . . . . . . . . . . 19 
CRITICAL HUMAN ORGAN RADIATION DOSIMETRY FOR THE

ACTIVE BONE MARROW *

\section{Abstract}

Critical Human Organ Radiation Dosimetry (CHORD) probability density functions for $A-P, P-A$, bilateral, rotational, and isotropic incidence, plus simple depth-dose data, permit the rapid estimation of the radiation insult to the active red bone marrow system of the: ICRF Reference Man. The CHORO concept follows the variations in the microscopic processes of absorption, attenuation, and scattering on a macroscopic level so that it is not necessary to attempt detailed calculations for each and every case of interest. Similar techniques have been applied to reactor criticality calculations and the general logic of the CHORD process can be applied to any cause-response type situation which can be described in terms of variation with distance in the medium of interest. Doses to active bone marrow from exposures to photons and neutrons are presented and excellent agreement was found with the few available experimental results.

\section{Introduction to the CHORD Concept}

When a bioorganism is subjected to a radiation environment, a critical organ or region of greatest risk usually is irradiated nonuniformly if the linear dimensions of the critical organ are not small or the depth of the critical organ within the bioorganism is not large compared with the mean-free pathlengths of the irradiating particles. Radiation insult specific analyses are usually based on dose to cells,

*Research sponsored by the Energy Research and Development Administration under contract with Union Carbide Corporation. 
a small target site or cluster of cells within an organ such as the mandible, or a center such as the central nervous, or active bone marrow system. For some effects, cells or sensitive sites within cells may not be irradiated uniformly because of discrete energy loss events and microdosimetric considerations (Rossi, 1975) may be desirable. On a more macroscopic scale, chronic effects such as bone sarcomas or even leukemia may, in some cases, be directly related to highly localiz̈ed exposures such as usually encountered in radiotherapy of tumors and the maximum absorbed dose at a particular site (mass of a gram as opposed to an intercellular site) may be more meaningful than the mean absorbed dose to the complete active marrow system (Wilson and Carruthers, 1962; A. R. Jones, 1975). Detailed distribution of photon dose to specific active marrow regions for A-P, $\mathrm{P}-\mathrm{A}$, rotational, and side (lateral) incidence have been published and should be readily applied to many situations of intercst (Jones et al., 1973; Clifford and Facey, 1970). Fur radiation protection and risk analyses from acute effects and those chronic effects where risk is thought to be proportional to the insult to the system such as usually assumed for leukemia, it is often not possible or desirable to establish insult-response type correlations on a microsconic level. Therefore, it becomes necessary to assign a "mean" insult or risk to a non-uniformly irradiated "critical organ".

One approach to the dosimetry of a non-uniformly irradiated critical organ, such as the red bone marrow system, is to use a probability density distribution of length, referred to as a CHORD length distribution. Any specific CHORD or $p\{l\}$ d $\ell$ distribution is 
obtained by assuming that the critical organ is simply a volume of . constant density, and for each differential unit of mass $\mathrm{dm}$, chosen by Monte Carlo techniques, the minimum distance $\ell$ to the closest irradiated air-tissue interface is uniquely determined. This process. is continued until $p\{l\} d \ell$ is well known statistically. Chord usually implies a straight line through two points on the surface, e.g., the skin; however, in this paper CHORD is an acronym derived from Critical Human Organ Radiation Dosimetry and represents only a specific portion of a "true Chord". The CHORD concept is illustrated in Figure 1 and the CHORD or $p\{\ell\} d \ell$ distribution provides "weighting" factors for an integration over a specific insult such as a "multicollision" depth-dose curve for the source geometry of interest.

\section{CHORD Applications to Red Bone Marrow}

Figure 2 illustrates the distribution of the active red bone marrow in the normal adult and the corresponding analog for our Monte Carlo transport code. In the adul.t reference man (ICRP, 1975) there are 1500 grams of active red marrow and 1500 grams of yellow marrow which are predominately fat cells. Inactive yellow marrow may be transformed quickly into active marrow by a stimulus such as bleeding or infection; yellow marrow in bone shafts is known to contain some active cells but, in general, the proportion of active cells in adult yellow marrow is usually considered to be small (Spiers, 1966). Thus, for most situations of interest, only the red marrow receives major consideration. 


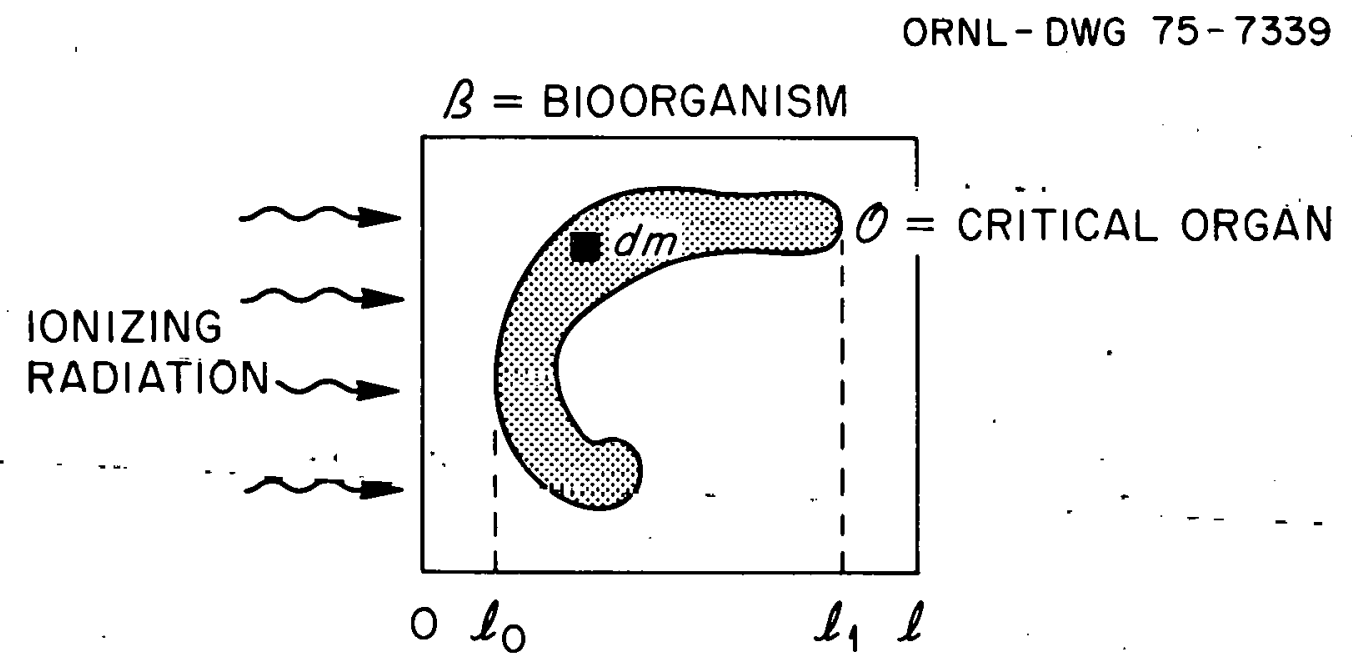

MULTICOLLISION DOSE $=O(\ell)$

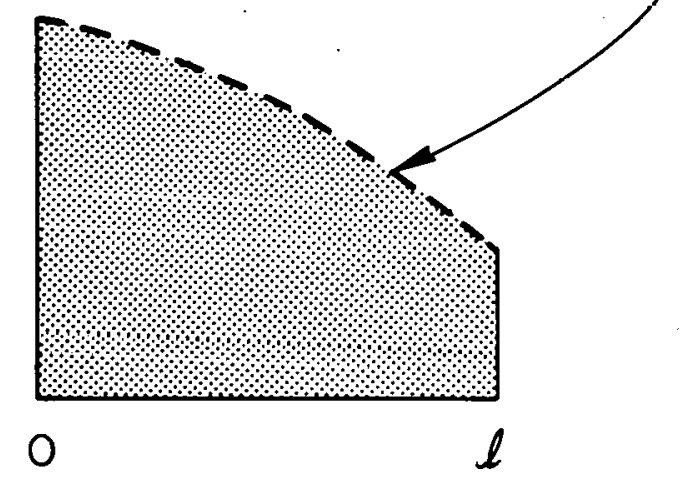

PENETRATION DISTANCE PENETRATION DISTANCE

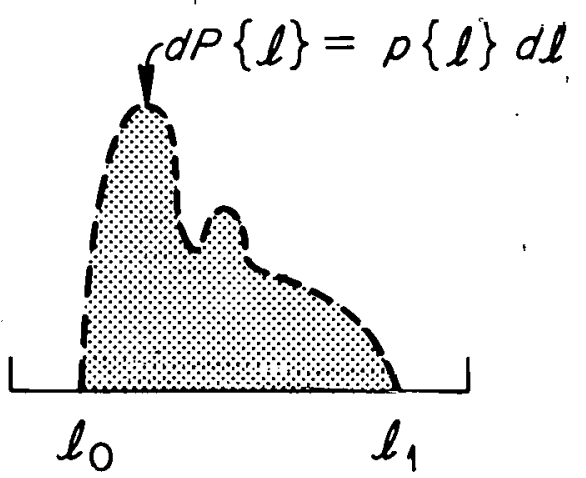

$$
\begin{aligned}
& \text { BUT } \ell=\ell(d m), \\
& \text { AND } \bar{D}=\int_{0} D(\ell) \cdot p\{l\} \cdot d \ell / \int_{-\infty}^{\infty} D\{l\} \cdot d \ell .
\end{aligned}
$$

Fig. 1. Critical Human Organ Radiation Dosimetry the CHORD Concept. 
ORNL - DWG 70-4810

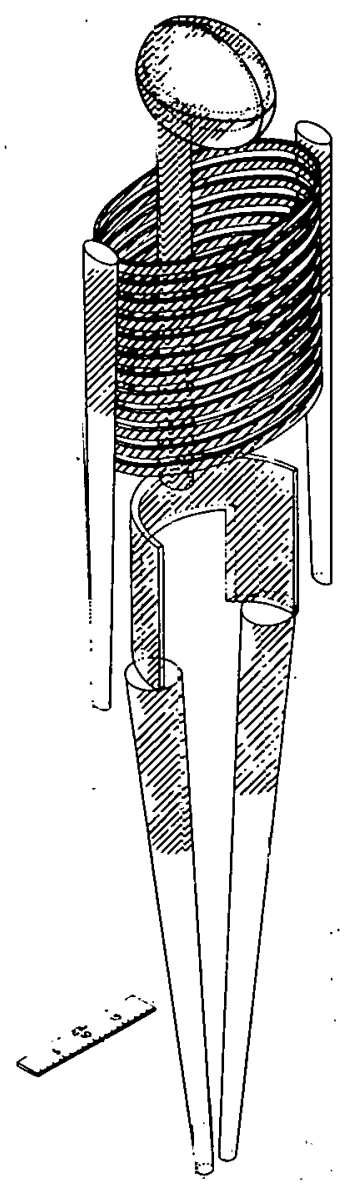

COMPUTER ANALOG OF REFERENCE MAN.
SKULL

VERTEBRAE

RIBS + STERNUM

SCAPULAE

HEAD AND NECK OF BOTH ARMS

BOTH CLAVICLES

HEAD AND NECK OF BOTH LEGS

PELVIS

TOTAL AMOUNT OF RED BONE MARROW: $1500 \mathrm{~g}$

RED BONE MARROW

$13.1 \%$

$28.4 \%$

$10.2 \%$

$4.8 \%$

$1.9 \%$

$1.6 \%$

$3.8 \%$

$36.2 \%$

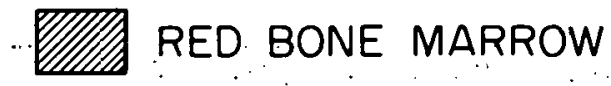

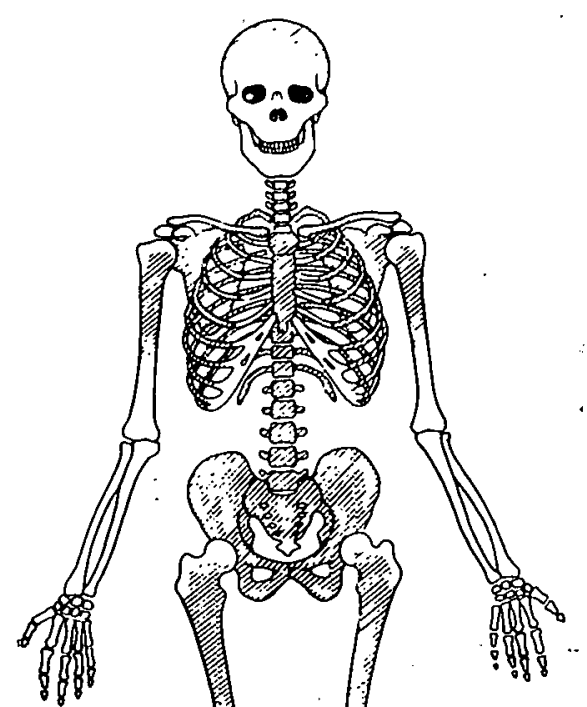

or

Fig. 2. Distributions of the Active Bone Marrow. 
The importance of a risk estimate based on radiation damage to the active marrow system cannot be overstated as bone marrow damage usually will be the major mechanism in radiation death and acute radiation sickness stemining from whole body irradiation because it occurs at much lower levels (Facey, 1968; Wald, 1975) than death or incapacitation due to radiation damage of the gut mucosa or the central nervous system. For sublethal criticality accident exposure levels, levels of interest in radiation protection, and population! exposure levels, the most demanding recommendations of the ICRP (196.4) relate to the maximum permissible doses to the gonads and the bluod= forming organs. In radiation protection, the testes are usually considered to be the critical organ of primary interest because of their shallow location and because of the difficulty of estimating the bone marrow insult; however, if the exposure level subjects an individual to considerable risk, then an estimation of the insult to his active marrow system could be advantageous for determining what medical treatment should be administered promptly (Wald, 1975).

The dose at a penetration depth of $5 \mathrm{~cm}$ is often chosen to describe the insult to the red bone marrow; however, for photon irradiation the "5 cm rule" is often in error by a factör of lwu and is expecter to be even worse for neutron irradiation. This approximation tends to retain popularity in spite of its inaccuracy, because the red marrow is distributed widely in the skeleton. The skeletal distribution shown in Figure 2 illustrates the ract that, in general, no specific depth can be applied for different exposure 
geometries and different irradiating particles or even different energies of particles having the same nature.

For internal dosimetry, especially for radionuclides deposited: in or near the skeleton, a precise calculational analog of the active. marrow system requires some postulations about cavity size variation and the distribution of these marrow cavities within the skeleton. However, for most situations of external exposure, the active marrow may be assumed to be uniformly deposited in certain regions of the skeleton. This simplification is possible because for external exposurc, distance versus insult (dose) variation is much less than. for internal radionuclide deposition where the insult (dose) usually varies even more rapidly than inversely with the square of the distance. There are two opposing effects that also influence the photon absorbed dose to marrow. These effects are the increased shielding by the bone structure and the enhancement of dose near the nigher atomic number bone tissue (Spiers, 1966; Wilson and Carruthers, 1962). As demonstrated later, the net influence of these opposing effects is usualily considered to be small for external exposure al though such is not always the case for internal emitters.

\section{CHORD Distribution and Marrow Doses}

Figure 3 and Table 1 present CHORD density functions for active marrow in the Referencc Man Phantom (ICKP, 1975) for A-P, P-A, bilateral, rotatinnal, and isotropic exposure. Due to the nature of the CHORD concept and the general convexness of the Reference Man Phantom, there is no differentiation between $2 \pi$ and $4 \pi$ CHORD distributions; however, depth-dose curves will reflect the different 

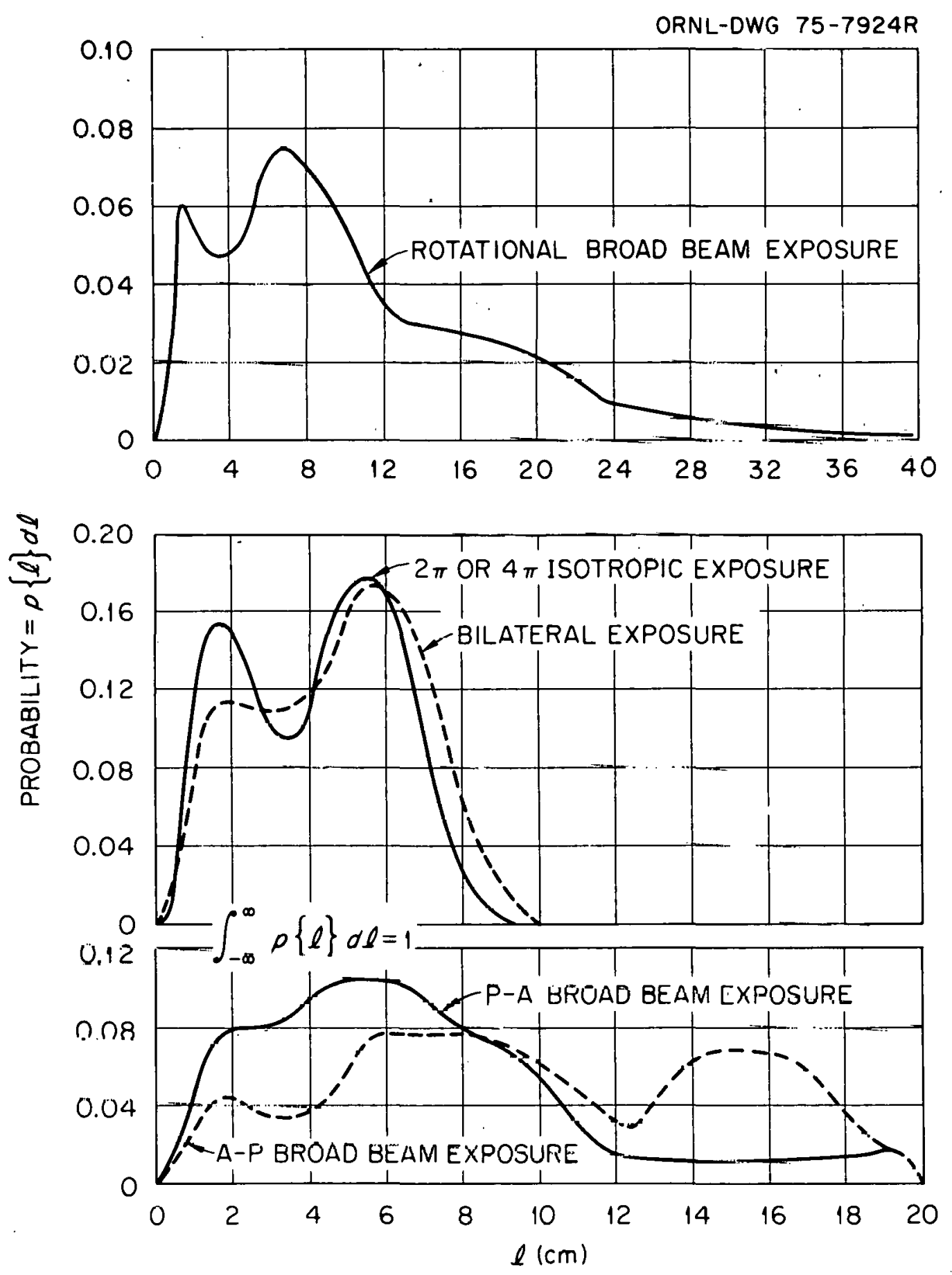

Fig. 3. CHORD Density Functions for Active Marrow in Reference Man. 


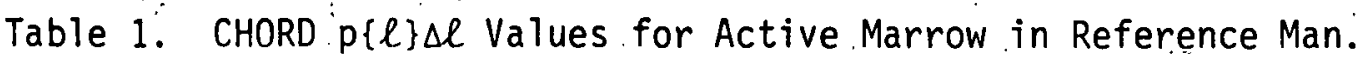

\begin{tabular}{|c|c|c|c|c|c|c|c|c|c|c|}
\hline$\ell(\mathrm{cm})$ & Rotational & cv & A-P & $\mathrm{cv}^{*}$ & P-A & $\mathrm{cv}$ & Bilateral & cv & Isotropic & $\mathrm{cv}$ \\
\hline $0-0.5$ & .00515 & 6 & .00626 & 3 & .00718 & 3 & 0.0138 & 2 & .0231 & 3 \\
\hline $0.5-1$ & .0175 & 3 & .0157 & 2 & .0252 & 1 & .0420 & 1 & .0658 & 2 \\
\hline $1-2$ & .0608 & 2 & .0412 & 2 & .0716 & 1 & .115 & 1. & .154 & 2 \\
\hline $2-3$ & .0508 & 3 & .0361 & 2 & .0791 & 1 & .114 & 1 & .126 & 2 \\
\hline $3-4$ & .0465 & 3 & .0340 & 2 & .0850 & 1 & .110 & 1 & .0944 & 2 \\
\hline $4-5$ & .0505 & 3 & .0442 & 2 & .107 & 1 & .133 & 1 & .152 & 2 \\
\hline $5-6$ & .0662 & 2 & $: 0730$ & 1 & .126 & 1 & .173 & 1 & .179 & 2 \\
\hline $6-7$ & .0744 & 2 & .0782 & 1 & .109 & 1 & .160 & 1 & .136 & 2 \\
\hline $7-8$ & .0705 & 2 & .0748 & 1 & .0806 & 1 & .0966 & 1 & .0586 & 2 \\
\hline $8-9$ & .0703 & 2 & .0738 & 1 & .0756 & 1 & .0359 & 2 & .0105 & 6 \\
\hline $9-10$ & .0603 & 2 & .0641 & 1 & .0626 & 1. & .00688 & 4 & & \\
\hline $10-11$ & .0482 & 3 & .0522 & 1 & .0440 & 2 & & & & \\
\hline $11-12$ & .0380 & 3 & .0364 & 2 & .0207 & 2 & & & & \\
\hline $12-13$ & .0311 & 3 & .0292 & 2 & .0127 & 3 & & & & \\
\hline $13-14$ & .0292 & 3 & .0549 & 1 & .0121 & 3 & & & & \\
\hline $14-15$ & .0282 & 3 & .0658 & 1 & .0119 & 3 & & & $\because$ & \\
\hline $15-16$ & .0268 & 4. & .0675 & 1 & .0123 & 3 & & & & \\
\hline $16-17$ & .0285 & 3 & .0643 & 1 & .0129 & 3 & &. & . & \\
\hline $17-18$ & .0283 & 3 & .0492 & .1 & .0130 & 3 & & & & \\
\hline $18-19$ & .0237 & 4 & . .0231 & 2 & .0154 & 3 & & & . & \\
\hline $19-20$ & .0241 & 4 & .0159 & 3 & .0168 & 2 & & & & \\
\hline $20-21$ & .0218 & 4 & . & & & & & & . & \\
\hline $21-22$ & .0169 & 4 & & & & & & " & & \\
\hline $22-23$ & .0135 & 5 & & & . & & & & . & \\
\hline $23-24$ & .00985 & 6 & & & & & & & & \\
\hline $24-25$ & .00866 & 6 & & & & & & & & \\
\hline $25-26$ & .00787 & 7 & & & & & & & & \\
\hline $26-27$ & .00672 & 7 & & & & & & & & \\
\hline $27-28$ & .00699 & 7 & & & & & & & & \\
\hline $28-29$ & .00545 & 8 & & & & & & & & \\
\hline $29-30$ & .00562 & 8 & & & & & & & & \\
\hline $30-31$ & .00385 & 9 & & & & & & & & \\
\hline $31-32$ & .00276 & 11 & & & & & . & ' & & \\
\hline $32-33$ & .00194 & 13 & & & & & & & 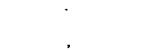 & \\
\hline $33-34$ & .00170 & 14 & & & & & & & 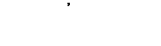 & \\
\hline $34-35$ & .00147 & 15 & & & & & & : & & \\
\hline $35-36$ & .00184 & 14 & & & & & & & & \\
\hline $36-37$ & .00126 & 16 & & & & $\cdot$ & & & & \\
\hline $37-38$ & .00164 & 14 & & & & & & & & \\
\hline $38-39$ & .000988 & 19 & & & & & & & & \\
\hline $39-40$ & .000341 & 32 & & & & & & & & \\
\hline
\end{tabular}

*Coefficient of variation in percent. 
exposure geometries. The peak at $2 \mathrm{~cm}$ for rotational and isotropic exposure is due to the shorter penetration distances to the side ribs and upper arm bones while the more important peak at about $6 \mathrm{~cm}$ is predominantly from the vertebrae and pelvis. The CHORD distributions are influenced strongly by the pelvic region and the thoracic vertebrae which contain about $36 \%$ and $28 \%$, respectively, of the total active marrow. In figure $3, l$ varies to $40 \mathrm{cII}$ for rotational exposure because it was assumed that rotational CHORD dose estimates will be obtained from broad beail depth-dose datin. For Lilatepal and isotropic exposures, $l$ varies to $10 \mathrm{~cm}$ because depth-dose data is expected to be related to the minimum distance to the closest irradiated surface.

The CHORD distributions from Figure 3 were used in conjunction with depth-dose curves (see Figure 1) according to

$$
D_{\text {red marrow }}=\sum_{\ell} D(\ell) \cdot p\{\ell\} \cdot \Delta \ell
$$

because all CHORD distributions were normalized to unity. Photon luse to the active marrow as predicted by llie CIIORD concopt is shown in Figure 4; however, bilateral and rotational results are not shown because of close agreement with the results for A-P exposure.

Figure 5 provides active marrow dose relative to exposure at the front of the chest for A-P incidence. A.lun Jones' experimental results (1964) are included and the mean deviation between the two methods is only $6 \%$ to $1.25 \mathrm{MeV}$ which is high into the Compton range 


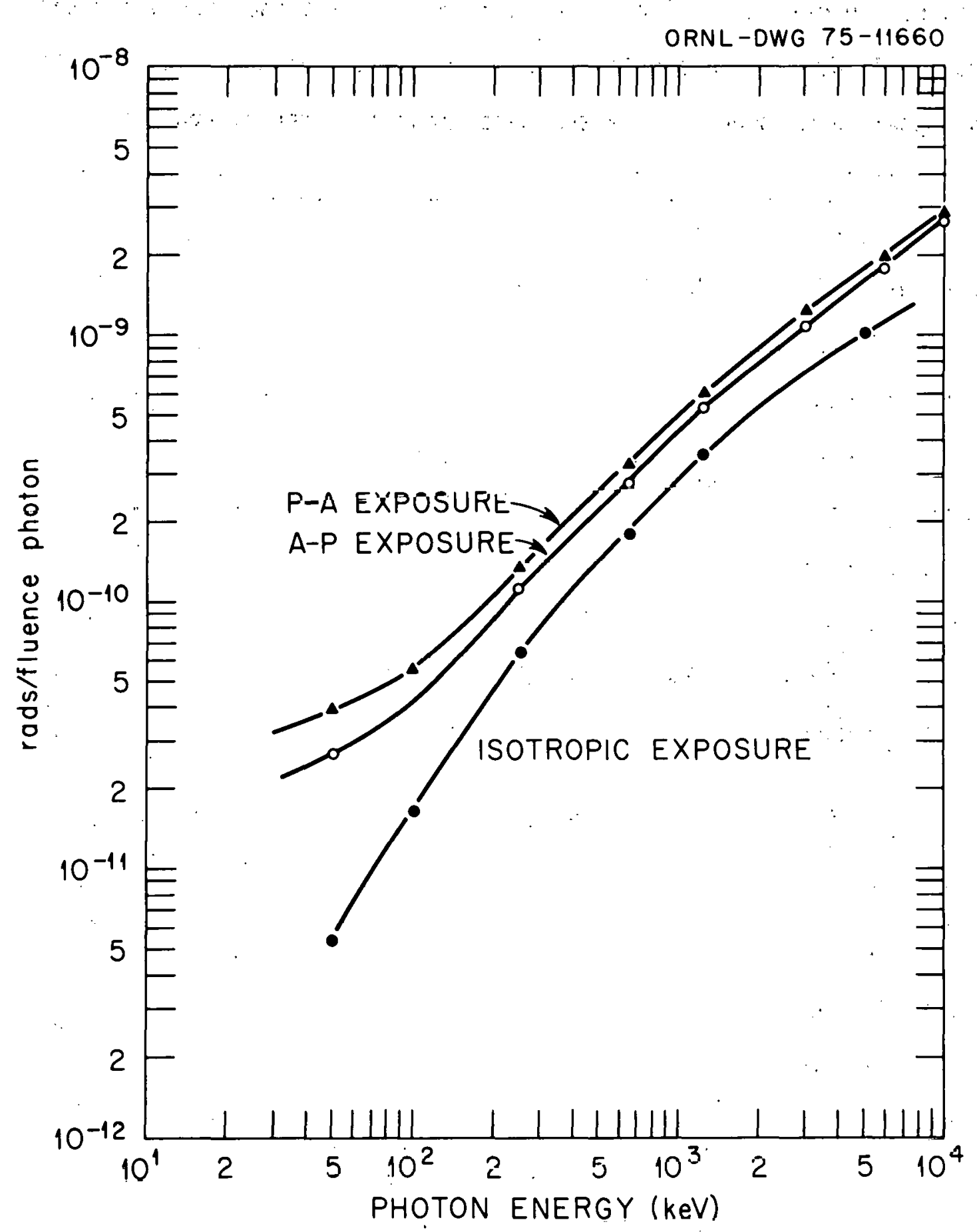

Fig. 4. Dose to Active Marrow as Predicted by the CHORD Concept. 


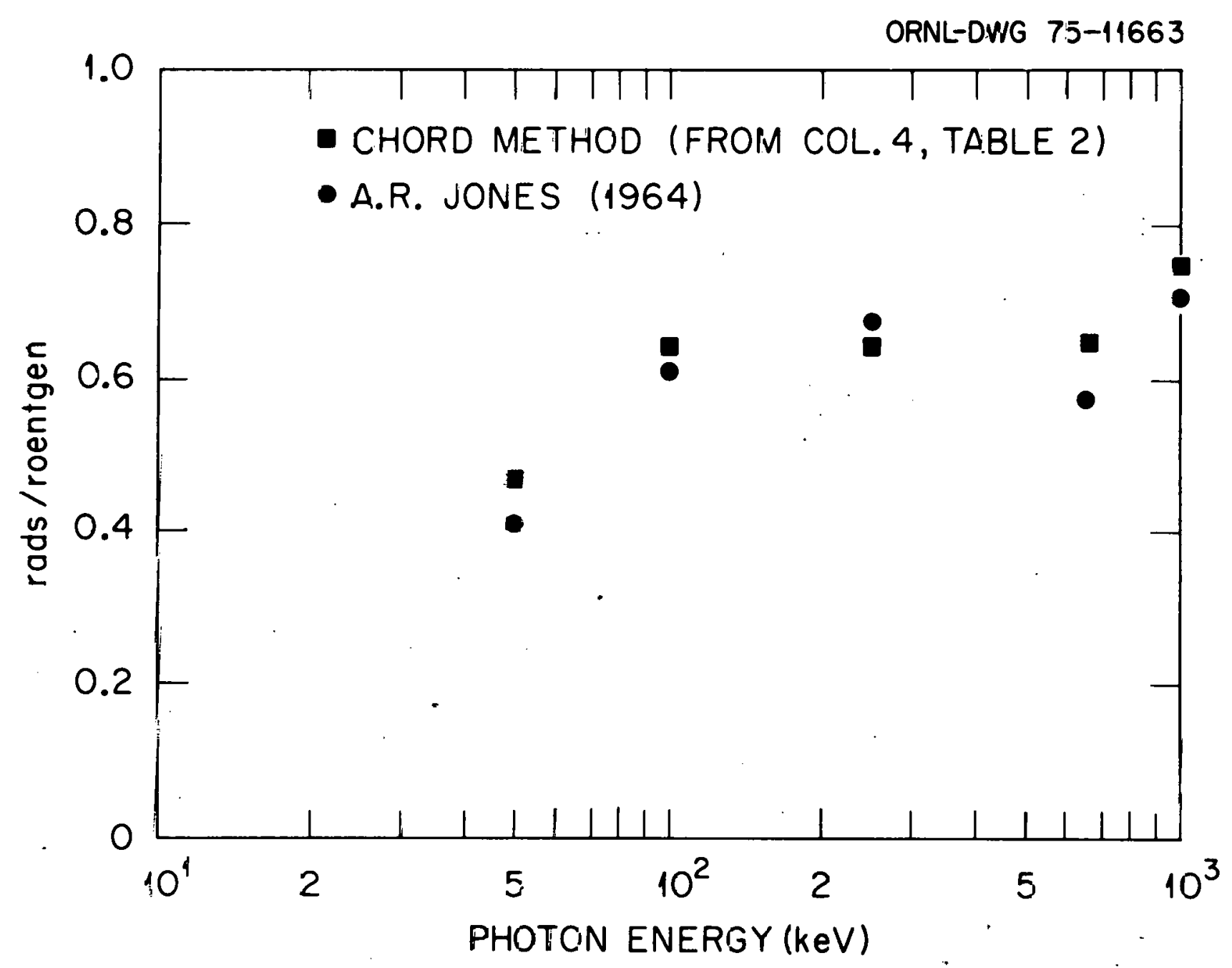

Fig. 5. Active Marrow Dose Relative tc Exposure at the Front of the Chest (A-P Exposure). 
shown in Figure 6 . Figure 6 is intended to serve as a guideline for applications of the method of CHORDs to critical regions in or near bone tissue. Experimental results were not available for higher energies. Column 4 in Table 2 represents estimates from the CHORD method and column 5 is from our Monte Carlo transport code (Jones, et al., 1973). These values shown in column 5 were calculated at the time of the cited reference but have not been published previously in. this form. The Monte Carlo results show excellent agreement in the photoelectric region (see Figure 6) but seem to become increasingily inaccurate in the Compton region. This unexpected characteristic of the Monte Carlo results defies explanation at this time but the effect will be investigated.

The important practical case of dose to the active marrow from broad beam incidence on a constantly rotating phantom is shown in Figure 7. Experimental results from Wilson and Carruthers (1962), Alun Jones (1964), and Facey (1968) may have suffered slight disfigurations due to replotting, but all appear to have been normalized to the same ordinate at $250 \mathrm{keV}$. Much concern has been expressed (Facey 1968) about whether marrow dose per unit exposure should increase monotonically with energy as noted by Wilson and Carruthers (1962) or whether it should peak at about $100 \mathrm{keV}$ as noted by Alun iones (1964). The different shapes have been considered due to energy degradation within the phantom and the fact that the detector systems of Alun Jones (1964) and Wilson and Carruthers had energy dependences in opposite directions (Facey, 1968). 


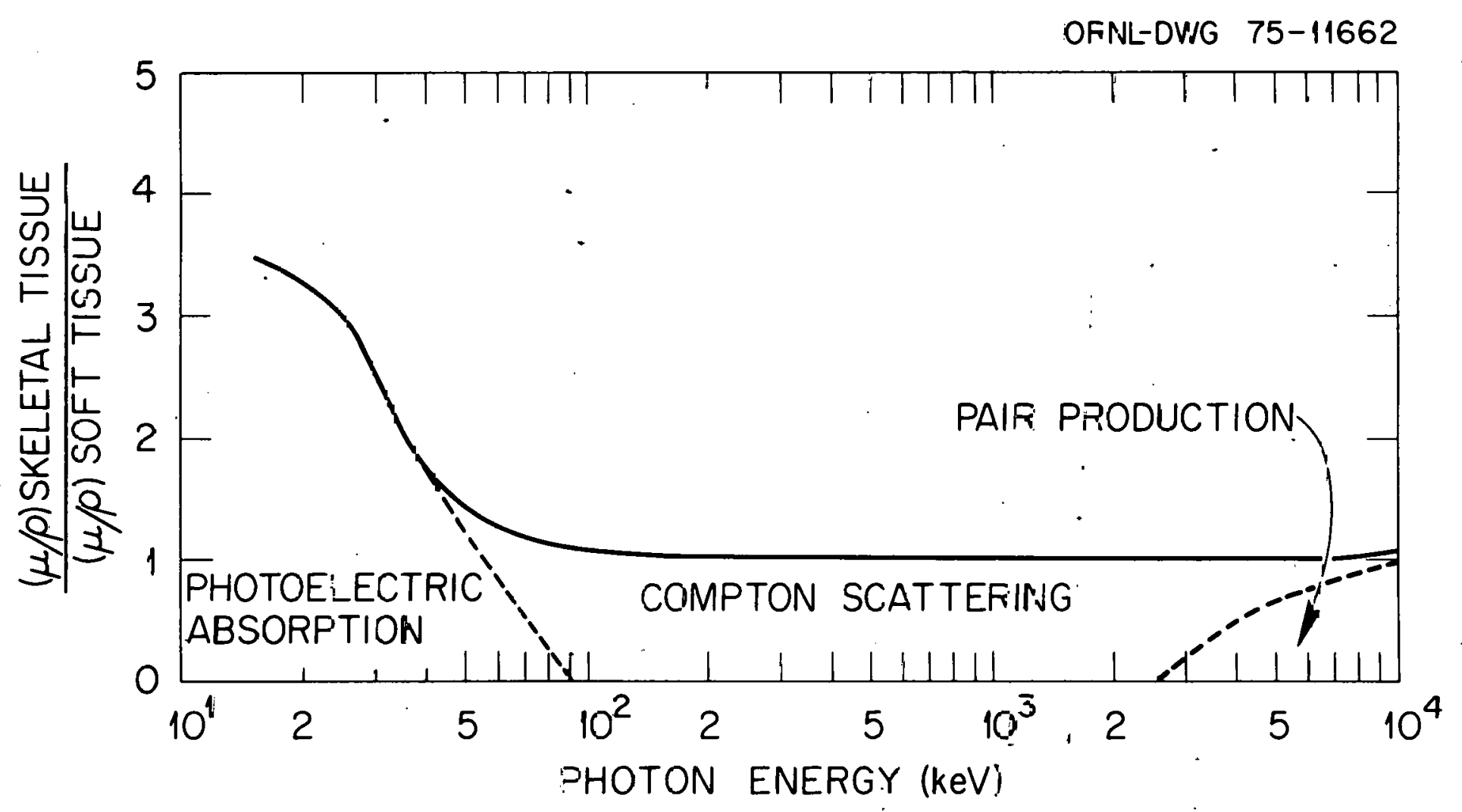

Fiq. 6. Phozan Attenuation of Skeletal Tissue Comparec to that of Soft Tissue. 
Table 2. Active Marrow Dose Relative to Dase at the Front of the Chest.

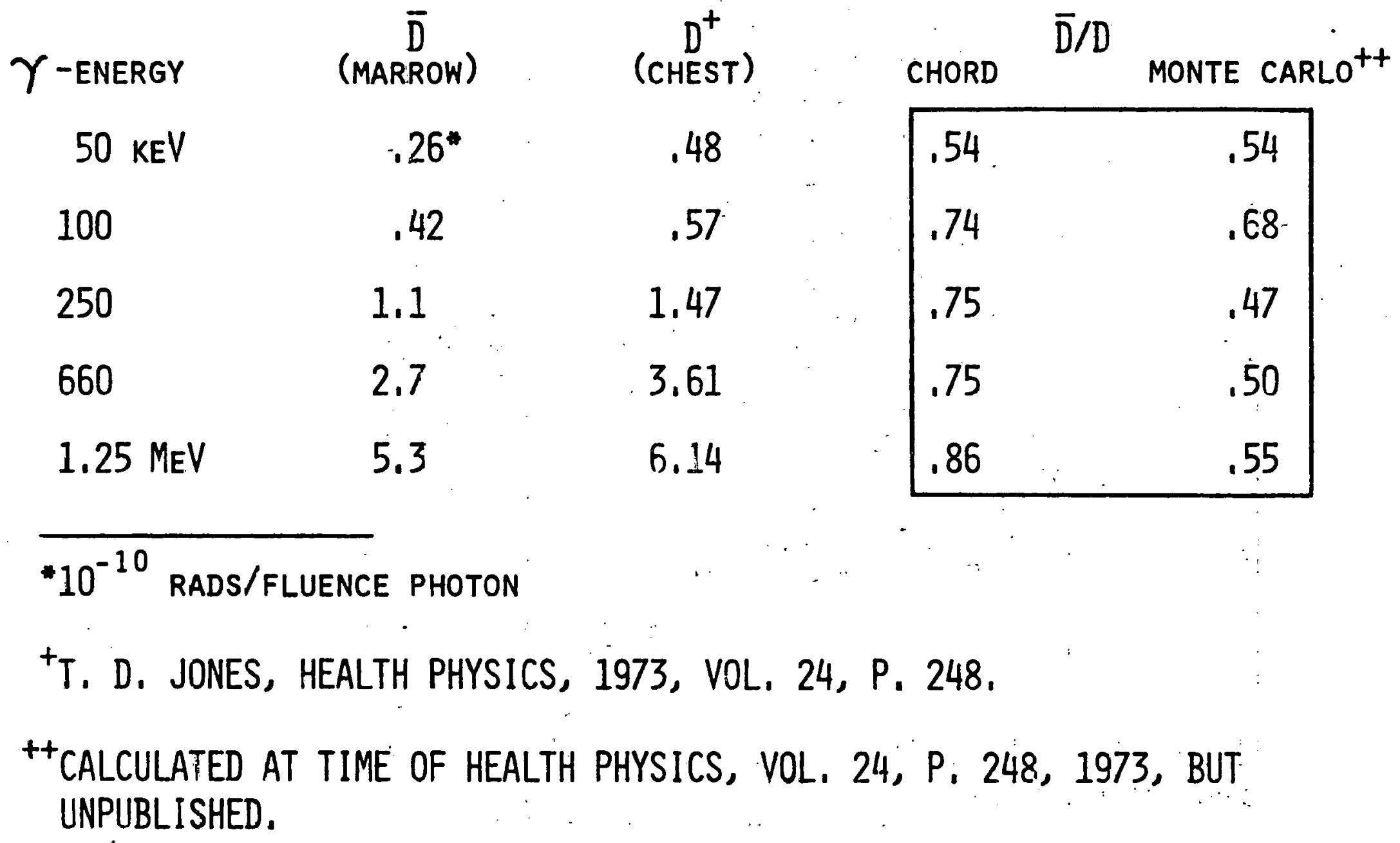


ORNL-DWG 75-11665

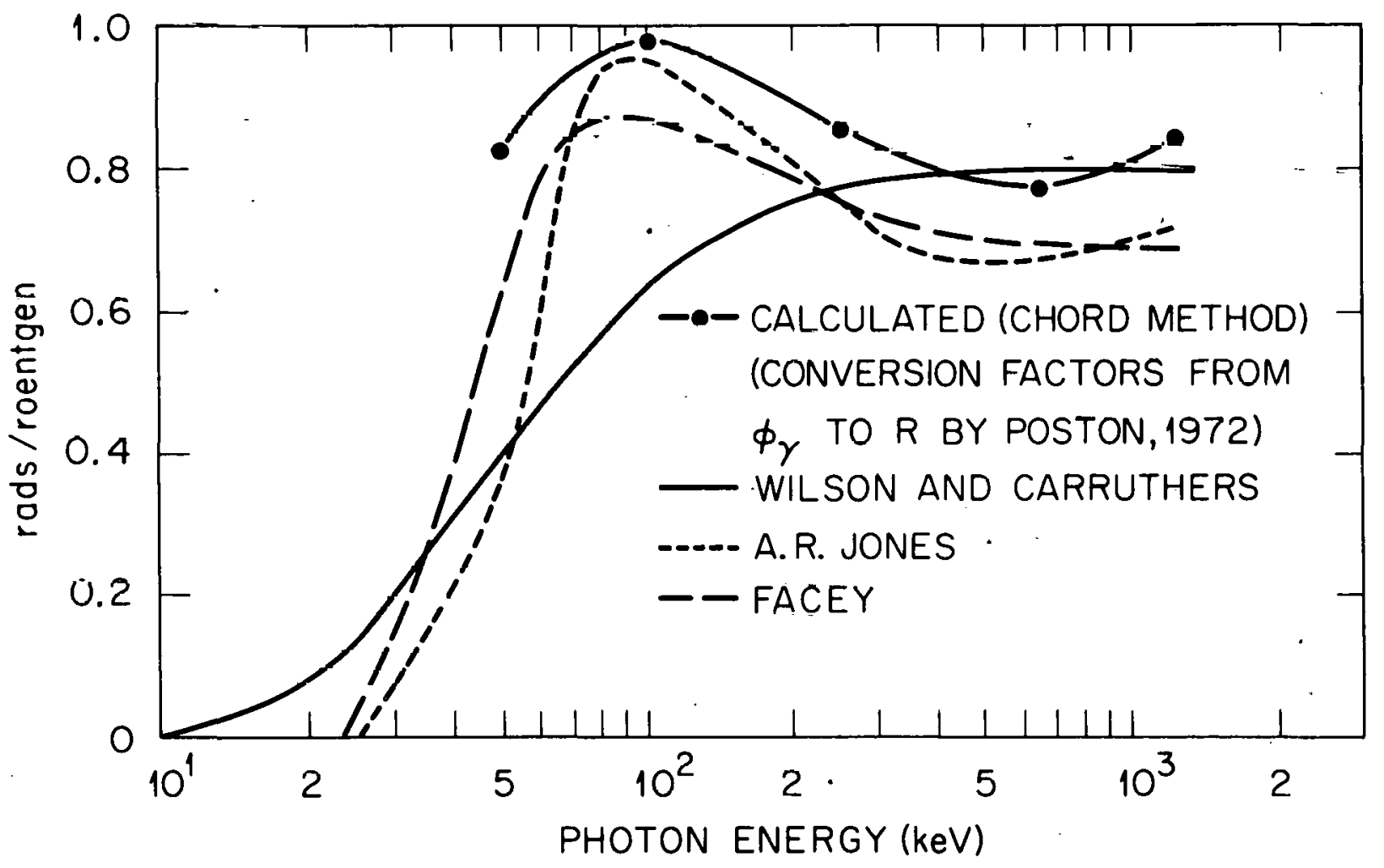

Fig. 7. Dose to Bune Marrow from a Broad Beam! Incident un a Rotating Phantom. 
At this time, it seems more probable that the different shapes are due primarily to the fact that if one considers the shape of the curve describing the ratio of the photon fluence per unit exposure as a function of photon energy (Rad. Health Hbk, 1970; Fair, 1967) then the dose response curve must have a shape that peaks about $100 \mathrm{keV}$ because the fluence per unit exposure varies more rapidly with energy than does the absorbed dose to the marrow, and secondarily to the fact that Wilson and Carruthers assumed that $60 \%$. of the active marrow received a dose similar to that measured in the thoracic vertebrae and 40\% received a duse simflar to that measured in the sternum*. The CHORD doses are in excellent agreement with Facey's results (1968), except for a consistent $12 \%$ overestimation. This deviation is attributed to the facts that (a) $13.1 \%$ of the active marrow is in the skull (see Figure 2) which Facey did not include, (b) experimental results from Facey appear to have been normalized to other experimental results at $250 \mathrm{keV},$. (c) experimentally obtained doses to the active marrow system necessitate the assumption of an "effective mass center" of each important marrow region (Clifford and Facey, 1970)**, and (d). the CHORD estimate did not allow for increased attenuation by bone tissue shielding the marrow. As seen in Figure. 6 ,

This method of averaging would tend to underestimate dose at lower energies because as Facey: (1968) points out, the "pelvis dominates dose at higher energies followed by the thoracic vertebrae and sacrum down to $30 \mathrm{keV}$. Therc the ribs enter second place and below 30 keV the ribs dominate." Facey (1968) attempted to resolve difficulties in the rotational case and his results are shown in Figure 7.

**For precision, this "effective mass center" would have to be "weighed" proportionally to dose variations in the local volume of interest; however, most experimenters appear to have used the mass centroid. 
this effect is not large except for extremely low energies. At the low energies, dose to the shallow marrow becomes increasingly important, as is shown by the rapid attenuation of dose as a function of depth, and must experimental results are expected to be somewhat low because of the method of averaging. CHORD dose values were normalized per unit exposure according to the Rad. Health Hdbk. $(1970)^{*}$. In spite of factors $a, b, c$, and $d$, excellent ayreement for A-P estimates (A. R. Jones, 1964) and rotatinnal estimates (Facey, 1968) compared with the method of CHORDs is observed. Figure 4, which. shows the dose to the active marrow for exposure to monoenergetic photons, suggests that if one is concerned only about protection of his bone marrow, he should not do the instinctive thing and turn his back, but instead should face the hazard while backing away. The same effect was also obscrved by Piesch (1968) and holds for the neutron data in Table 3 which illustrates dose to the actlve marrow from exposure to monoenergetic neutrons. Some of the data in Table 3 are plotted in Figure 8 for ease of application. Bilateral and rotational results are not shown in Figure 8 because of their close agreement with the results for $A-P$ exposure. Absorbed dose from neutron produced recoit ions is usually characterized by the hydrogen atomic density, berause about $70 \%$ of the absorbed dose is due to interactions with hydrogen atoms for neutron energies below $14 \mathrm{MeV}$ (Auxier, 1968; Jones, 1974). Standard soft muscle tissue contains about $10 \%$ by

\footnotetext{
*Poston's conversion values of fluence per unit exposure for the Reference Man tissue composition are, for all practical purposes, equal to those in the Rad. Health Handbook.
} 
Table 3. Dose to Active Marrow from Neutron Produced Recoil Ions as Predicted by CHORD Distributions.

\begin{tabular}{|c|c|c|c|c|c|c|}
\hline ENERGY & $\begin{array}{l}\text { FREE-SPACE * } \\
\text { KERMA }\end{array}$ & $P-A^{* *}$ & $A-P$ & BI LATERAL & ROTATIONAL & I SOTROPIC \\
\hline $.025 \mathrm{EV}$ & 2.1 & 2.1 & 1.2 & 1.4 & 1.6 & .70 \\
\hline $1 \mathrm{KEV}$ & 1.0 & 3.3 & 2.2 & 2.1 & 2.3 & 1.1 \\
\hline $10 \mathrm{KEV}$ & 10. & 4.1 & 2.6 & 2.6 & 2.8 & 1.6 \\
\hline $10 \cap \mathrm{KEV}$ & 70. & 12. & 7.4 & 9.4 & 9.2 & 5.4 \\
\hline $1 \quad$ MeV & 230. & 110. & 67. & 74. & 75. & 47. \\
\hline $2,5 \mathrm{MEV}$ & 340. & 240. & 180. & 150. & 190. & 84. \\
\hline $14 \mathrm{MEV}$ & 690. & 590. & 520. & 420, & 540. & 330. \\
\hline
\end{tabular}

* $x 10^{-9}$ ERgs/(GRAM-FLUENCE NEUtRON)

* $\times 10^{-11}$. RADS/FLUENCE NEUTRON 


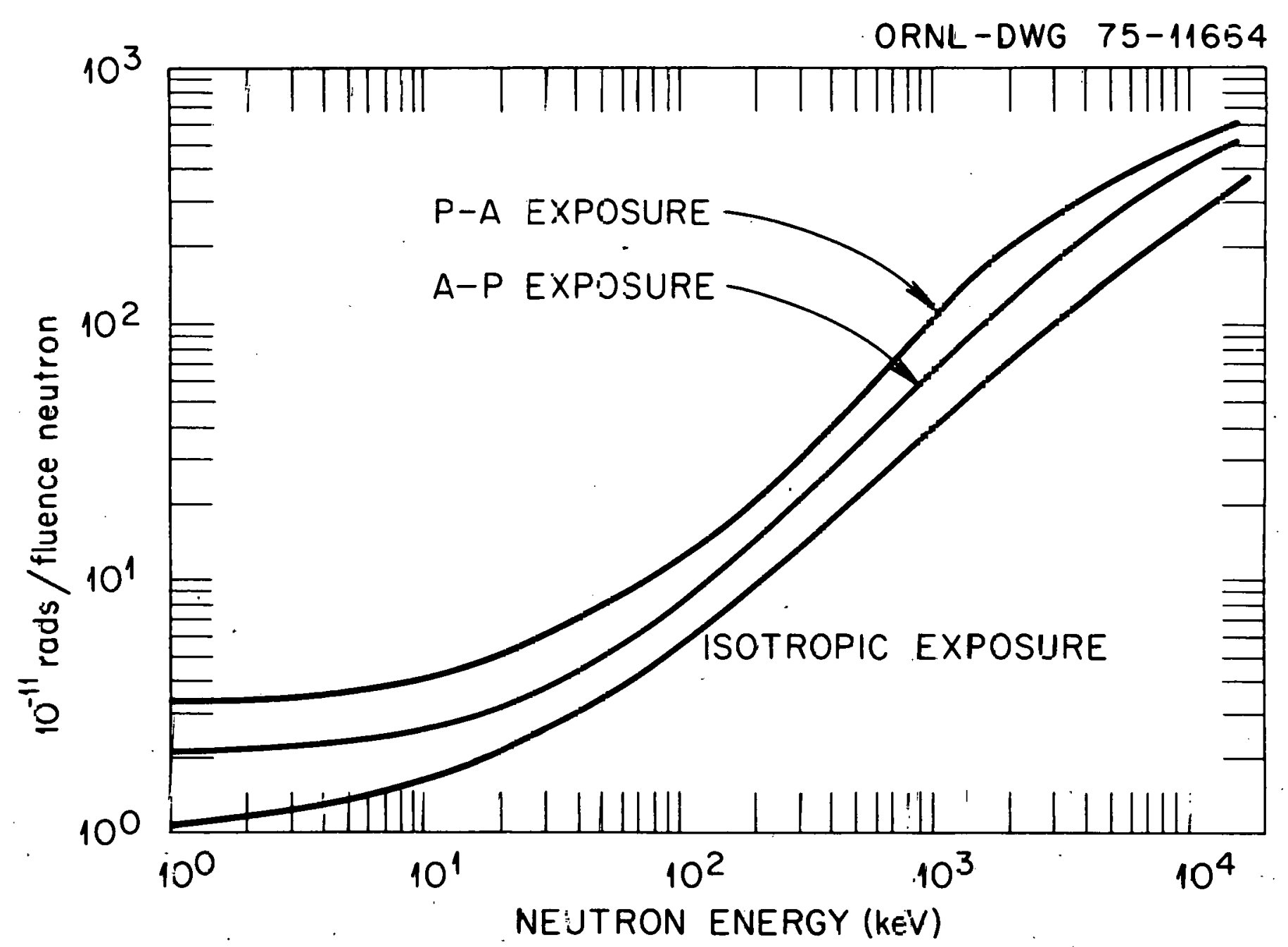

Fig. \&. Dose from Recail Ians to the Active Marrow as Predicted by the CHORD Concept. 
weight hydrogen and has a specific gravity of unity, while bone tissue contains about one-half the weight percentage of hydrogen as does muscle tissue but has about twice the specific gravity of muscle tissue so that the hydrogen atomic density is not very different for the two types of biological tissue. Lung tissue has a specific gravity of only about 0.3 and the hydrogen atomic density, therefore; is quite different; however, most critical organs of interest are either distant from the lung tissue or closer to an irradiated surface so that the penetration distance in $\mathrm{grams} / \mathrm{cm}^{2}$ is less than the other portiun: of the ray of travel that passes through a section of the lungs. Based on depth-dose curves from some of our previous calculations (Jones et al., 1973), it is believed that most regions of variable specific gravity do not significantly influence the application of the method of CHORDs, unless one is specifically interested in dose to a volume of lung tissue.

Other CHORD Applications

Figure 9 illustrates a proposed dosimeter or "riskmeter" in which the relative settings of the outer two dials select the appropriate CHORD distribution and the inner two dials select the insult (depthdose) curve for the energy and type of incident radiation. Alun Jones (1966) suggested that dosimetry should be approached by matching vartations in dose or risk with scattering, absorption, and attenuation; however, the CHORD method seems to permit this same precision of matching variability on a simplified macroscopic level. Hopefully a schema such as incorporated into Figure 9 would render the absorbed dose index, $D_{I}$, and dose equivalent index, $H_{I}$, for 


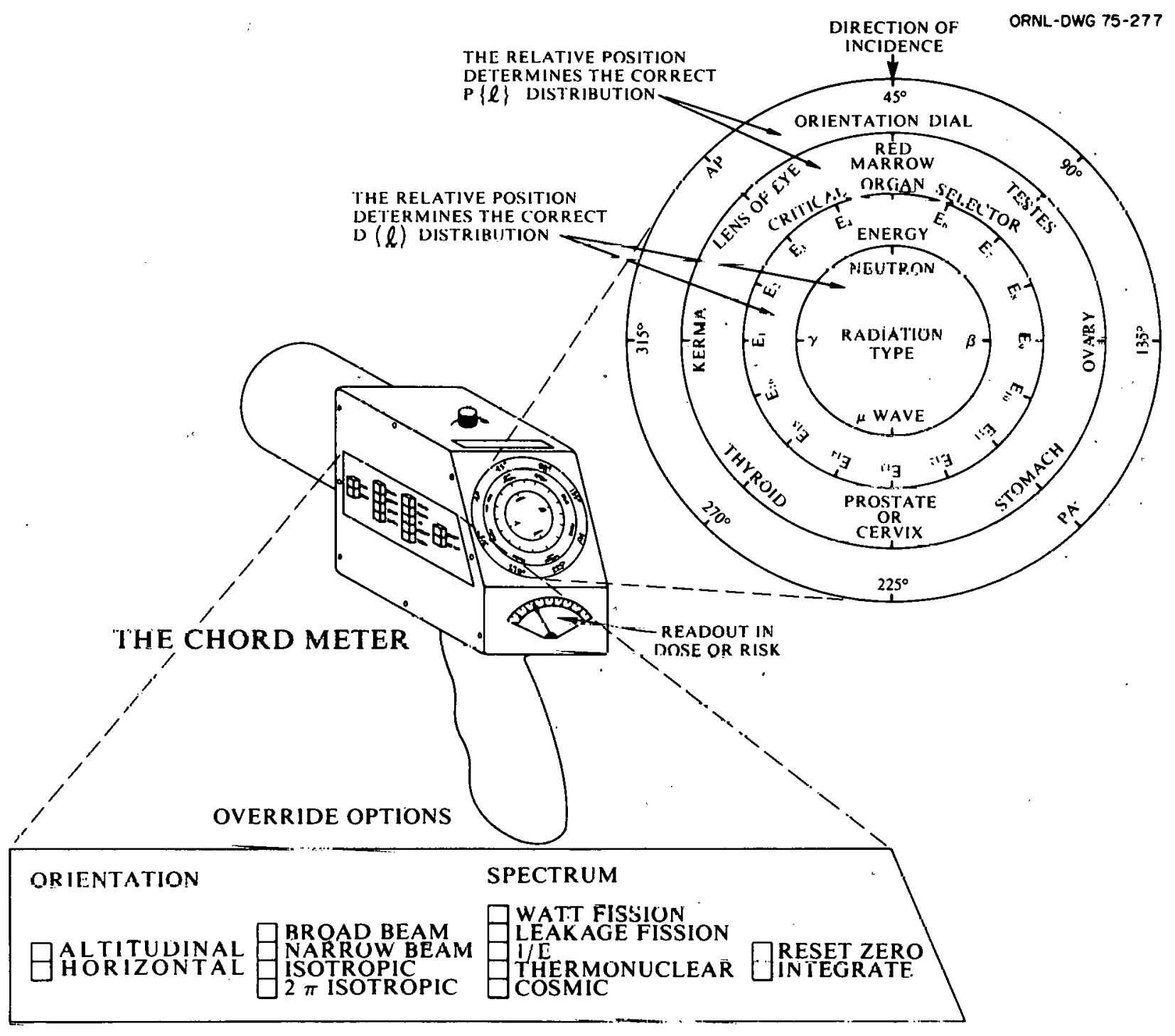

Fig. 9. Critical Human Organ Radiation Dosimeter. 
the standard ICRU $30 \mathrm{~cm}$ sphere (ICRU, 1971) even less useful than it already is, because by ușing CHORD density functions plus standard insult: (multicollision. depth-dose) curves, a health physicist or medical technician could easily and quickly estimate exposure values to any biological tissue at risk. It is also becoming apparent that significant calculational and experimental efforts will soon be directed to the estimation of tissue risk due to microwave irradiations and the availability of $p\{l\}$ de distributions should be helpful.

\section{Conciusions}

In summary, the method of CHORDs permits rapid "critical organ" dose estimation and helps to circumvent some of the problems of relating organ dose or risk to readings from meters or film badges. A personal dosimeter measures exposure at the surface of the chest; the measured exposure corresponds neither to the exposure in free space nor to the organ or whole body dose and area dosimeters determine only free space exposure (Piesch, 1967). Alun Jones (1966, 1964) pointed out that a survey meter or personal dosimeter may overestimate the insult to the active marrow by a factor of 10 or underestimate by a factor of 6 . In spatially dependent radiation fields, or for exposure to broad beam sources having an orientation other than A-P, it is usually very difficult to have an accurate risk estimate because of normalization to an inaccurate or shielded reading taken at the location of the chest. 
Acknowledgments

This paper is heavily dependent upon the experimental work of Wilson, Carruthers, Facey and Alun Jones for the discussion of the results and as a means of estimating the validity of the CHORD concept. It is also necessary to acknowledge the helpful suggestions and data supplied by Alun Jones and J. W. Poston. 


\section{References}

Clifford, C. E., and Facey, R. A., 1970, Health Physics 18, 217.

Facey, R. A., 1968, Health Physics $14,557$.

Fair, M., 1967, in Principles of Radiation Protection, Ed. K. Z. Morgan and J. E. Turner, Chap. 3 (John Wiley and Sons).

ICRP Publication 6, 1964, Recommendations of the International Commission on Radiological Protection, (Pergamon Press).

ICRP Publication 23, 1975, Report of the Task Group on Reference Man, (Pergamon Press).

ICRU Report 19, 1971, Radiation Quantities and Units.

Jones, A. R., 1964, AEC.I -2240.

Jones, A. R., July 30, 1975, Personal communication to T. D. Jones.

Jones, T. D., Auxier, J. A., Snyder, W. S., and Warner, G. G., 1973, Health Physics 24, 241.

Piesch, E., 1968, Health Physics 15, 145.

Poston, J. W., 1972, Personal communication of fluence per unit exposure conversion factors for Reference Man tissue composition.

Radiological Health Handbook, 1970, U.S. Department of Health, Education, and Welfare, Public Health Service Consumer Protection and Environmental Health Service, Rockville, MD.

Spiers, F. W., 1966, Rad. Research 28, 624.

Wald, N., 1975, "Newer Biological Indicators of Radiation Damage," Refresher course given at Annual Meeting of Health Physics Society, Ju1y 13-17, 1975.

Wilson, R., and Carruthers, J. A., Health Physics I, 171, 1962. 


\section{THIS PAGE}

WAS INTENTIONALLY

LEFT BLANK 
ORNL/TM-5337

INTERNAL DISTRIBUTION

1- 2. Central Research Library

3. Document Reference Section, CRL

4- 6. Laboratory Records

7. Laboratory Records, ORNL, RC

8. ORNL Patent Office

9. J. A. Auxier

10. J. L. Hwang

11. D. G. Jacobs

12-17. T. D. Jones

18-22: G. D. Kerr

23. J. W. Poston

24. C. R. Richmond

25. D. K. Trubey

EXTERNAL DISTRIBUTION

26-52. Technical Information Center, Townsite

53. Research and Technical Support Division, ORO, ERDA

54. L. R. Allen, Radiation Effects Research Foundation, 5-2 Hijiyama Koen, Hiroshima 730, Japan

55. Lowell Anderson, Dept. of Medical Physics, Memorial Hospital for Cancer and Allied Diseases, Sloan-Kettering Institute for Cancer Research, New York, NY

56. T.'W. Armstrong, Science Applications, Inc., P. 0: Box 2351, 1200 Prospect Street, La Jolla, CA. 92037

57. F. H. Attix, Code 6603 A, Nucl. Science Div., Naval Research Lab., Washington, DC 20390

58. Donald E. Barber, Environmental Health, School of Public Health, 1325 Mayo Memorial Bldg., Minneapolis, MN 55455

59. G. W. Beebe, National Academy of Sciences, Washington, DC 20418

60. David E. Bernhardt, EPA, Box 15027, Las Vegas, NV 89114

61. Tom B. Borak, Biology and Medical Division, Argonne National Lab., 9700 South Cass Avenue, Argonne, IL 60439

62. James T. Brennan, University Hospital, Dept. of Radiology, 3400 Spruce Street; Philadelphia, PA 19104

63. H. D. Bruner, USERDA, Washington, DC 20545

64.. W. W. Burr, Jr., USERDA, Washington, DC 20545

65. R. L. Butenhoff, USERDA, Washington, DC 20545

66. A. B. Chilton, University of Illinois, Urbana, IL

67. C. E. Clifford, Defense Research Establishment, Defense Research Board, Ottawa 4, Canada

68. George Cuwper, Head, Health Physics Branch, Atomic Energy of Canada, Ltd., Chalk River Nuclear Lab., Chalk River, Ontario KOJ IJO, Canada

69. Roger Cloutier, Special Training Division, ORAU

70. W. G. Cross, Atomic Energy of Canada, Ltd., Chalk River Nuclear Lab., Chalk River, Ontario KOJ IJO, Canada 
71. Desmond R. Davy, AAEC, HPR. Section, Private Mail Baq, Sutherland N.S.W., Australia

72. J. A. Dennis, National Rad. Prot. Board, Harwe11, Berkshire, England

73. Marc H. Dousset, Center d'Etudes Nucleaire, Department de la Protection Sanitaire, Service d'Hygiene Atomique, B.P. $N^{\mathrm{C}} 6$, Fontenay - aux - Roses, France

74. R. A. Facey, Defense Research Establishment, Defense Research Board, Ottawa 4, Canada

75. S. B. Field, MRC Cylcotron Unit, Hammersmith Hospital, London, England

76. S. C. Finch, Radiation Effects Research Foundation, 5-2 Hijiyama Koen, Hiroshima 730, Japan

77. N. A. Trigerio, Arqonne National Lab., 9700 South Cass Avenue, Argonne, IL 60439

78. R. V. Griffith, Lawrence Livermure Lab., IIniversity of California, P. 0. Box 808, Livermore, CA 94550

79. Ferenc Hajnal, HASL, ERDA, 376 Hudson Street, New York, NY 10014

80. Dale Hankins, 312 Portrillo Drive, Los Alamos, NM 87544

81. Tadashi Hashizume, National Institute of Radiological Sciences, Chiba 280, Japan.

82. William R. Hendee, Dept. of Radiology, University of Colorado Medical Center, 420 East Ninth Avenue, Denver, Colorado 80220

83. G. H. Herling, Code 6665, Navy Department, Naval Research Lab., Washington, DC . 20390

84. H. E. Ing, Atomic Energy of Canada, Ltd., Chalk River Nuclear Lab., Chalk River, Ontario KOJ IJO, Canada

05. H. Jammet, Commissariat a l'Energie Atomique, Centre d'Etudes Nucleaire de Fontenay - aux - Roses, France

86. A. R. Jones, Health Physics Branch, Atomic Energy of Canada. Ltd., Chalk River Nuclear Lab., Chalk River, Ontario KOJ IJO, Canada

87. Dean Kaul, Science.Applications, 5005 Newport Drive, Suite 305, Rolling Meadows, IL 60008

88. Sadahisa Kawamoto; Radiation Effects Research Foundation, 164 Sakurababa-mach1, Nagasaki 8.50, Japan

89. T. J. Kenriedy, Jr., National Academy of Sciences, Washington, DC 20418

90. Laszlo Koblinger, Health Physic.s Dept., Central Research Institute for Physics, P. 0. Box 49, 1525 Budapest, Hungary

91. Andrzej Kreft, Institute of Nuclear Technology, Academy of Mining and Metallurgy, Cracow, Al. Mickiewicza 30, Poland

92. Lawrence H. Lanz1, The Frank1 In McLeani Memorial Research Institute, University of Chicago, 950 E. 59th Street, Chicago, IL 60637

93. R. C. Lawson, UKAEA, Chapelcross, Annon, Scotland

94. J. L. Liverman, USERDA, Washington, DC 20545

95. Z. Makra, Central Research Institute for Physics, Budapest XII, Konkoly Thege ut, Hungary

96. Sidney Marks, USERDA, Washington, DC 20545

97. C. W. Mays, Radiobiology Lab., University of Utah, Salt Lake City, Utah 84112 
98. P. H. McGinley, Emory University Clinic, Department of Rad. Therapy, 1365 Clifton Rd., N.E., Atlanta; GA 30322

99-108. I. M. Moriyama, Radiation Effects Research Foundation, 5-2 Hijiyama Koen, Hiroshima 730 , Japan

109. Ladislov. Musilek, Technical University of Prague, Faculty of Technical and Nuclear Physics, Brehovd 7 - Praha 1, Czechoslovakia

110. Dieter Nachtiga11, Stahlenschutz, Euratom 2 BKM, Steenweg naar, Retie, Geel/Belgium

111. Keren 0'Brien, Health and Safety Lab., USERDA, New York, NY 10014

112. Ing. F. Pernicka, Laboratory for Radiological Dosimetry of the Czechoslovak Academy of Sciences, Praha 8, Na Truhlarce 39/2a Czechoslovakia

113. E. Piesch, Karlsruhe Nuclear Research Center, Rad. Monitoring Service, Federal Republic of Germany

114. S. Pretre, Research Institute for Protective Construction, 8001 Zurich, Switzerland

115. H. H. Rossi, Professor of Radiology, College of Physicianls and Surgenns of Columbia University, 630 West 168th Street, New York, NY 10032

116. W. J. Russell, Radiation Effects Research Foundation, 5-2 Hijiyama Koen, Hiroshima 730, Japan

117. E. L. Saenger, Radioisotope Lab., Cincinnati General Hospita? and University of. Cincinnati College of Medicine, Cincinnati, OH 45267

118. J. W. Smith, AERE, Harwe11, Didcot, Berks., England

119. Kenji Takeshita, Research Institute for Nuclear Medicine and Biology, Hiroshima University, Hiroshima 734, Japan

120. Arnie Warshawsky, U.S. Army Agency, Fort Bliss, El Paso, TX

121. D. E. Watt, UKAEA, Chapelcross, Annon, Scotland

122. F. S. Williamson, Division of Biological and Medical Research, Argonne National Lab., 9700 South Cass Avenue, Argonne, IL 60439

123. R. Wilson, Defense Research Chemical Laboratory, Ottawa, Canada

124. R. W. Wood, USERDA, Washington, DC 20545

125. Hisao Yamashita, Radiation Effects Research Foundation, 5-2 Hijiyama Koen, Hiroshima 730, Japan

126. T. 0. Young, Atomic Weapons Research Establishment, Bldg. A29.1, Aldermaston, Reading RG74PR, United Kingdom 